\title{
EFFECT OF JASMONIC ACID AND YEAST EXTRACT ELICITATION ON LOW-MOLECULAR ANTIOXIDANTS AND ANTIOXIDANT ACTIVITY OF MARJORAM (ORIGANUM MAJORANA L.)
}

\author{
Urszula Złotek ${ }^{\bowtie}$ \\ Department of Biochemistry and Food Chemistry, University of Life Sciences in Lublin \\ Skromna 8, 20-704 Lublin, Poland
}

\begin{abstract}
Background. Elicitation, which is a way of inducing plant secondary metabolism, may be an effective method for improving the quality of plant food. The aim of this study was to determine how the application of jasmonic acid (as an abiotic elicitor) and yeast extract (as a biotic elicitor) influences the production of some bioactive compounds in marjoram and the antioxidant activity of this herb.

Material and methods. Elicitation with $0.01 \mu \mathrm{M}$ and $1 \mu \mathrm{M}$ jasmonic acid as well as $0.1 \%$ and $1 \%$ yeast extracts was used for improving the health-benefiting quality of marjoram. The study focused on the effects of eliciting the level of some phytochemicals and the antioxidant activity of marjoram.

Results. There were no significant differences in total phenolic content between the elicited and control plants. In turn, the elicitation with $0.1 \%$ and $1 \%$ yeast extracts caused 1.8 - and 2.5 -fold increases in the ascorbic acid content in marjoram leaves, respectively. Both biotic and abiotic elicitation resulted in elevation of chlorophyll content, but only the abiotic elicitor (jasmonic acid) caused a significant increase (by over $50 \%$ ) in the carotenoid content of marjoram leaves. The antiradical activity of marjoram was increased by the abiotic and biotic elicitation, whereas only the abiotic elicitation resulted in improving the reducing power of this herb.

Conclusions. In conclusion, biotic and abiotic elicitation could be an effective strategy for improving the level of some phytochemicals, as well as the antioxidant activity of marjoram. A particularly valuable finding obtained in this study is that natural elicitors e.g. yeast extract can be equally effective in elevating the content of some bioactive compounds in herbs e.g. marjoram as an abiotic one.
\end{abstract}

Keywords: antioxidant activity, elicitation, low-molecular weight antioxidants, marjoram

\section{INTRODUCTION}

Marjoram (Origanum majorana L.), commonly known as sweet marjoram, is a plant from the Lamiaceae family, which is cultivated mainly for its aromatic leaves used for culinary purposes (Prerna and Vasudeva, 2015). This herb has been traditionally used, especially in India, for thousands of years for the treatment of gastrointestinal disturbances, cough, and bronchial diseases (Saxena et al., 2016). Some studies indicate that marjoram possesses many properties that are beneficial in some diseases, such as diabetes or Alzheimer's, and has anticancer, antihypercholesterolemic, and antihypertensive activity. Marjoram exerts antimicrobial, antioxidant, insecticidal, antifungal effects as well (Hossain et al., 2012; Saxena et al., 
2016). As in the majority of aromatic medicinal plants, the pro-health properties of this herb are attributed to its chemical composition. Among the biologically active compounds present in medicinal plants, vitamins, polyphenolics, carotenoids, and components of essential oil should be mentioned (Nowak and Ogonowski, 2010; Prerna and Vasudeva, 2015). However, phenolic compounds and components of essential oils are the main antioxidant constituents of marjoram, as well as phytochemicals like vitamin $\mathrm{C}$, carotenoids or chlorophylls (whose level can be influenced by environmental conditions) may play a role in the biological activity of this herb (Nurzyńska-Wierdak et al., 2012; Prerna and Vasudeva, 2015).

It is well-known that the concentration of phytochemicals in plants can be influenced by many factors, e.g. genetic and climatic factors, mode of cultivation, harvest phase, as well as various biotic and abiotic stresses (e.g. water stress, wounding, UV-light exposure; Baenas et al., 2014). Due to its low cost and simplicity, elicitation has become popular. Elicitors can be biotic or abiotic and natural or synthetic; therefore, they can be used in different crop systems. Moreover, plant response depends on the type of the elicitor used, the species or variety of plant, and the time of the elicitor application (Zhao et al., 2005; Złotek and Świeca, 2016).

Jasmonic acid (JA) is a phytohormone that not only can act as an elicitor in exogenous application, but also plays a significant role in plant growth and development as an endogenous compound (Malekpoor et al., 2016; Zhao et al., 2005; Złotek et al., 2016).

There is growing interest in using some natural elicitors in the induction of plant resistance and in the overproduction of phytochemicals by plants. Between them, in agricultural practices there are attempts to apply some products of natural origin, such as seaweed extracts, yeast extracts or willow bark extract for improving the quality and resistance of plants (Gawlik-Dziki et al., 2013; Kocira et al., 2016; Świeca, 2016; Złotek and Świeca, 2016), but this practice has still not been introduced in herb production.

The aim of the present study was to determine how JA and yeast extract (YE) influences the production of some bioactive compounds in marjoram and the antioxidant activity of this herb.

\section{MATERIAL AND METHODS}

\section{Plant material and growth conditions}

The yeast extracts used for elicitation were made according to Gawlik-Dziki et al.'s method (2013) - instant yeast Saccharomyces cerevisiae was dissolved in distilled water at concentrations of $0.1 \%$ - YE1 and $1 \%-$ YE2 (w/v) and autoclaved. JA solutions (at concentrations of $0.01 \mu \mathrm{M}-\mathrm{JA} 1$ and $1 \mu \mathrm{M}-\mathrm{JA} 2$ ) were prepared in deionized water (previously dissolved in very small amounts of ethanol $-1 \mathrm{~mL}$ and dispersed in appropriate volumes of water to achieve desirable concentrations). These elicitor preparations with a $0.01 \%$ $(\mathrm{v} / \mathrm{v})$ solution of Tween-20 as a surfactant were used in the elicitation of marjoram plants.

The marjoram seeds (Origanum majorana L., var. French) were obtained from PNOS Ożarów S.A., Poland. The seeds were sown into containers filled with universal soil for sowing seeds. Seven-day-old seedlings were moved to pots $(600 \mathrm{~mL})$ with universal garden soil (four plants per pot). The plants were grown in a growth chamber (SANYO MLR-350H) at $25 / 18^{\circ} \mathrm{C}$, photoperiod $14 / 10 \mathrm{~h}$ day/night, with a photosynthetic photon flux density (PPFD) at a plant level of 500$700 \mathrm{mmol} \mathrm{m} \mathrm{m}^{-2} \mathrm{~s}^{-1}$, and a relative humidity of $70 \%$. The control (C1) and jasmonic acid-elicited (JA1 and JA2) plants were fertilized twice (before transplantation and one week after transplantation) using standard fertilizers at the following levels $\left(\mathrm{mg} \mathrm{L}^{-1}\right): \mathrm{N}-110$, $\mathrm{P}-50, \mathrm{~K}-100$, and $\mathrm{Mg}-70$. The second control (C2) and yeast extract-elicited (YE1 and YE2) plants were watered with $3.5 \%$ of organic-mineral fertilizers (Biohumus forte) every four days. Twenty one-day-old plants were sprayed with elicitor solutions $(1.5 \mathrm{~mL}$ per plant). The control plants (C) were sprayed with only Tween-20 dissolved in deionized water. The concentrations of elicitors were selected based both on the literature (Złotek and Świeca, 2016; Złotek et al., 2014) and on previous screening experiments (data not shown), so as not to lead to negative effects on the health and growth of plants. Fifteen days after the elicitation, the herbs (leaves) were collected, frozen $\left(\right.$ at $-50^{\circ} \mathrm{C}$ ), and used in further analyses. The experiments were conducted in triplicate between January and April 2016. 


\section{Determination of plant yield}

Before harvest, plant height was determined (20 plants were measured from each object). After harvest, the herb was weighed, and freeze-dried $\left(-46^{\circ} \mathrm{C}, 50 \mathrm{mi}-\right.$ crobars, about 24 hours), then weighed again to obtain the total dry weight. The results were expressed as g plant ${ }^{-1}$.

\section{Analysis of low-molecular weight antioxidants}

\section{Extraction and determination of the content of phenolic}

Extraction procedure. Frozen herb samples $(2 \mathrm{~g})$ were homogenized with $10 \mathrm{ml}$ of $50 \%$ ethanol, after which phenolics were extracted for $1 \mathrm{~h}$ at $4^{\circ} \mathrm{C}$ and centrifuged at $10000 \mathrm{~g}$ for $30 \mathrm{~min}$. This procedure was repeated two times and the supernatants were combined and used for further analysis of the phenolics content and antioxidant capacity.

Determination of total phenolic compounds (TPC). The content of total phenolics was determined using Folin-Ciocalteau reagent (Singleton and Rossi, 1965) and calculated as gallic acid equivalents (GAE) in $\mathrm{mg}$ per $g$ of fresh weight (FW).

Extraction and determination of ascorbic acid (AA) content. The ascorbic acid content was determined using HPLC analysis according to the methods described by Campos et al. (2009). It was expressed in $\mathrm{mg}$ per $\mathrm{g}$ of fresh weight (FW).

Extraction and determination of the content of chlorophylls (chl) and carotenoids (car). Chlorophylls (chl) and car were analyzed according to the method described by Lin et al. (2013). The levels of $\operatorname{chl} a, \operatorname{chl} b$, and car were expressed in mg per $100 \mathrm{~g}$ of fresh weight (FW).

\section{Antioxidant activities}

Free radical scavenging activity was measured using 1,1-diphenyl-2-picrylhydrazyl (DPPH) as a source of free radicals according to Brand-Williams et al. (1995), while the reducing power (RP) was determined with the method described by Oyaizu (1986). The antioxidant activities were expressed as Trolox equivalents in $\mu \mathrm{mol}$ per $\mathrm{g}$ of fresh weight (FW).

\section{Statistical analysis}

All results were mean \pm S.D. of three independent experiments $(n=9)$. One-way analysis of variance (ANOVA) and Tukey's post-hoc test were used to evaluate statistical significance.

\section{RESULTS}

The results indicated that the elicitation with JA and YE did not affect the height of the marjoram plants (Table 1). In the case of fresh weight, elicitation with YE had a positive effect, although a statistically significant increase in this parameter was observed in the YE2-elicited plants, i.e. there was an approx. 2.5-fold increase (Table 1). In turn, in the case of analysis of the dry weight of the studied plants, all elicitors applied at the studied concentrations caused a significant increase in this parameter - Table 1 .

The contents of total phenolics, ascorbic acid, chlorophylls, and carotenoids in the marjoram leaves elicited with JA and YE are presented in Table 2. There were no significant differences in TPC between the elicited and control plants. In turn, the elicitation with YE1 and YE2 caused a significant increase in the ascorbic acid content (an approx. 1.8-fold and 2.5 -fold increase in comparison to the organic-mineral fertilized control $-\mathrm{C} 2$, respectively) - Table 2 . In the $0.1 \%$ yeast extract-elicited marjoram, the highest content of chlorophylls was also detected, where an increase of c. $48 \%, 36 \%$, and $44 \%$ was observed for chl $a$, chl $b$, and chl $a+b$, respectively, compared to the C2 sample (Table 2). The chlorophyll $a$ and total chlorophyll contents were also significantly increased as a result of the JA1 and YE2 treatments, whereas there was no significant difference in the chlorophyll $b$ content between the control and the elicitor-treated groups, except for the induction with YE1 (Table 2). In turn, only the abiotic elicitors (JA1 and JA2) caused a significant increase in the carotenoid content in the marjoram leaves.

Low molecular weight antioxidants determine the antioxidant potential of herbs, including marjoram. JA elicitation improved the antiradical activity of the marjoram leaf extracts most effectively: there was a 2-fold increase in this capacity in the JA1 and JA2 samples in comparison to the $\mathrm{C} 1$ sample (Fig. 1). The JA elicitation had a positive effect on reducing power, 
Złotek, U. (2017). Effect of jasmonic acid and yeast extract elicitation on low-molecular antioxidants and antioxidant activity of marjoram (Origanum majorana L.). Acta Sci. Pol. Technol. Aliment., 16(4), 371-377. http://dx.doi.org/10.17306/J.AFS.2017.0505

Table 1. Growth parameters of marjoram plants elicited with jasmonic acid and yeast extract

\begin{tabular}{lccc}
\hline & $\begin{array}{c}\text { Plant height } \\
\mathrm{cm}\end{array}$ & $\begin{array}{c}\text { Plant fresh weight } \\
\text { g/plant }\end{array}$ & $\begin{array}{c}\text { Plant dry weight } \\
\text { g/plant }\end{array}$ \\
\hline $\mathrm{C} 1$ & $14.00 \pm 0.50^{\mathrm{a}}$ & $0.40 \pm 0.04^{\mathrm{a}}$ & $0.051 \pm 0.002^{\mathrm{b}}$ \\
$\mathrm{C} 2$ & $0.36 \pm 0.06^{\mathrm{a}}$ & $0.074 \pm 0.005^{\mathrm{c}}$ \\
$\mathrm{JA} 1$ & $0.57 \pm 0.06^{\mathrm{a}}$ & $0.112 \pm 0.005^{\mathrm{d}}$ \\
$\mathrm{JA} 2$ & $11.30 \pm 0.61^{\mathrm{a}}$ & $0.45 \pm 0.23^{\mathrm{a}}$ & $0.099 \pm 0.03^{\mathrm{a}}$ \\
$\mathrm{YE} 1$ & $13.17 \pm 1.26^{\mathrm{a}}$ & $0.67 \pm 0.11^{\mathrm{ab}}$ & $0.091 \pm 0.003^{\mathrm{a}}$ \\
YE2 & $13.67 \pm 4.04^{\mathrm{a}}$ & $0.92 \pm 0.11^{\mathrm{b}}$ & $0.157 \pm 0.006^{\mathrm{e}}$ \\
\hline
\end{tabular}

$\mathrm{C} 1$ - standard fertilized control, C2 - organic-mineral fertilized control, JA1 - $0.01 \mu \mathrm{M}$ jasmonic acid, JA2 $-1 \mu \mathrm{M}$ jasmonic acid, YE1 $-0.1 \%$ yeast extracts, YE $2-1 \%$ yeast extracts.

Mean \pm standard deviation. Statistically significant differences (in column; $P<0.05$ ) indicated various letters.

Table 2. Influence of jasmonic acid and yeast extract elicitation on total phenolic compounds (TPC), ascorbic acid (AA), chlorophyll (chl), chl $a, \operatorname{chl} b$, and carotenoids (car) contents in marjoram leaves

\begin{tabular}{lcccccc}
\hline & TPC & AA & Chl $a$ & Chl $b$ & Chl $a+b$ & Car \\
\cline { 2 - 6 } & $\mathrm{mg} \mathrm{g}^{-1} F W$ & $m g 100 \mathrm{~g}^{-1} \mathrm{FW}$ & & & & \\
\hline $\mathrm{C} 1$ & $11.31 \pm 0.90^{\mathrm{a}}$ & $32.53 \pm 3.11^{\mathrm{ab}}$ & $223.91 \pm 1.69^{\mathrm{a}}$ & $105.95 \pm 11.96^{\mathrm{a}}$ & $329.86 \pm 12.64^{\mathrm{a}}$ & $23.71 \pm 3.90^{\mathrm{b}}$ \\
$\mathrm{C} 2$ & $11.57 \pm 1.93^{\mathrm{a}}$ & $38.29 \pm 0.12^{\mathrm{bc}}$ & $223.08 \pm 22.03^{\mathrm{a}}$ & $100.33 \pm 8.71^{\mathrm{a}}$ & $323.41 \pm 30.72^{\mathrm{a}}$ & $31.77 \pm 3.07^{\mathrm{ab}}$ \\
$\mathrm{JA} 1$ & $12.71 \pm 1.20^{\mathrm{a}}$ & $27.83 \pm 4.62^{\mathrm{ab}}$ & $272.06 \pm 26.32^{\mathrm{b}}$ & $115.68 \pm 9.03^{\mathrm{a}}$ & $387.74 \pm 35.31^{\mathrm{c}}$ & $36.99 \pm 2.50^{\mathrm{a}}$ \\
JA2 & $13.13 \pm 1.63^{\mathrm{a}}$ & $24.71 \pm 0.13^{\mathrm{a}}$ & $240.02 \pm 8.04^{\mathrm{ab}}$ & $98.28 \pm 12.94^{\mathrm{a}}$ & $338.30 \pm 18.74^{\mathrm{ab}}$ & $36.31 \pm 12.03^{\mathrm{a}}$ \\
YE1 & $11.78 \pm 1.41^{\mathrm{a}}$ & $52.16 \pm 9.74^{\mathrm{d}}$ & $331.02 \pm 6.20^{\mathrm{c}}$ & $136.58 \pm 2.84^{\mathrm{b}}$ & $467.59 \pm 8.83^{\mathrm{d}}$ & $39.23 \pm 1.88^{\mathrm{a}}$ \\
YE2 & $11.67 \pm 0.52^{\mathrm{a}}$ & $49.67 \pm 0.95^{\mathrm{cd}}$ & $269.70 \pm 4.87^{\mathrm{b}}$ & $113.91 \pm 1.49^{\mathrm{a}}$ & $383.61 \pm 5.72^{\mathrm{bc}}$ & $35.90 \pm 0.15^{\mathrm{ab}}$ \\
\hline
\end{tabular}

$\mathrm{C} 1$ - standard fertilized control, C2 - organic-mineral fertilized control, JA1 - $0.01 \mu \mathrm{M}$ jasmonic acid, JA2 - $1 \mu \mathrm{M}$ jasmonic acid, YE $1-0.1 \%$ yeast extracts, YE2 $-1 \%$ yeast extracts.

Mean \pm standard deviation. Statistically significant differences (in column; $p<0.05$ ) indicated various letters.

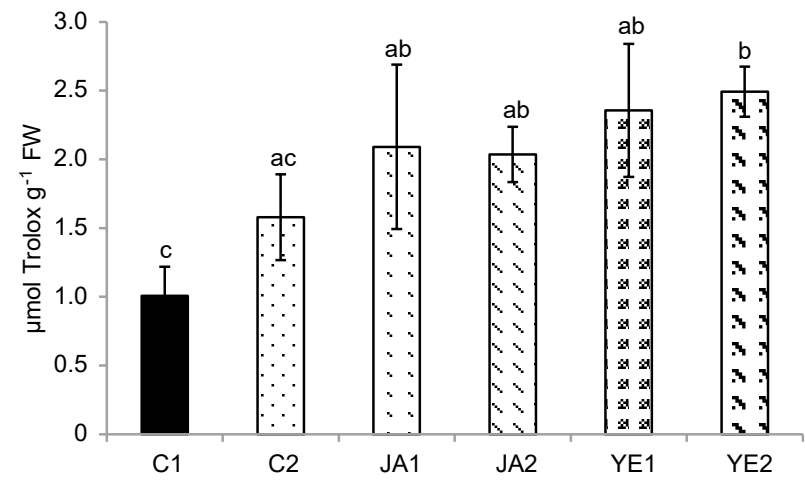

Fig. 1. The effect of biotic and abiotic elicitation on the antiradical activity of marjoram leaf extract: $\mathrm{C} 1$ - standard fertilized control, C2 - organic-mineral fertilized control, JA1 $-0.01 \mu \mathrm{M}$ jasmonic acid, JA2 $-1 \mu \mathrm{M}$ jasmonic acid, YE1 $-0.1 \%$ yeast extracts, YE2 $-1 \%$ yeast extracts. Mean \pm standard deviation. Statistically significant differences (in column; $P<0.05)$ indicated various letters 


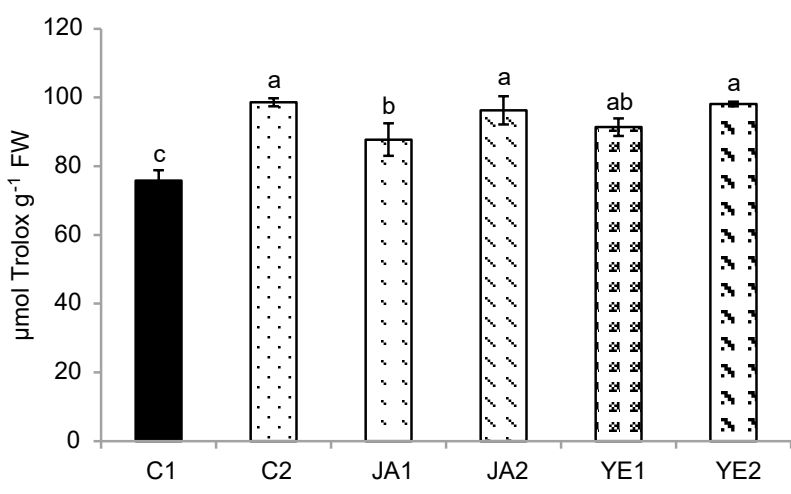

Fig. 2. The effect of biotic and abiotic elicitation on the reducing power of marjoram leaf extracts: $\mathrm{C} 1$ - standard fertilized control, C2 - organic-mineral fertilized control, JA1 $-0.01 \mu \mathrm{M}$ jasmonic acid, JA2 $-1 \mu \mathrm{M}$ jasmonic acid, YE1 $-0.1 \%$ yeast extracts, YE2 $-1 \%$ yeast extracts. Mean \pm standard deviation. Statistically significant differences (in column; $p<0.05$ ) indicated various letters

where an increase of c. $15.7 \%$ and $27 \%$ was observed for the JA1 and JA2 samples, respectively, compared to the $\mathrm{C} 1$ sample (Fig. 2). It should also be noted that the highest reducing power was detected for the extract from the control plants fertilized with the mineral-organic fertilizer $\left(\mathrm{C} 2 ; 98.62 \mu \mathrm{mol}\right.$ Trolox $\mathrm{g} \mathrm{FW}^{-1}$; Fig. 2).

\section{DISCUSSION}

Elicitation has been reported in in vitro plant cultures as a strategy for overproduction of some secondary metabolites with documented pro-health properties, but there is also growing interest in employing this tool for improving the quality of plant food, e.g. vegetables, fruits, or herbs (Angelova et al., 2006; Kim et al., 2006; 2007).

Since the use of elicitors activates the same pathways in plants as various types of stress, plant yields may be affected in this way.

Some reports suggest that elicitation may reduce crop yields (De Román et al., 2011); therefore, it is important to evaluate crops whether such treatment is used in the production of herbs or other edible plants. The biotic and abiotic elicitors (JA and YE) used in the present study had no negative impact on the yield of marjoram (Table 1). Additionally, it should be noted that a positive effect on the plant yield was obtained in some cases (Table 1). Similarly, the research conducted by Ali et al. (2009) indicated that foliar spray of some polyamines together with $\mathrm{NaCl}$ effectively increased dry matter of shoots, roots, and flowers of Origanum majorana. However, in the study by Złotek and Świeca (2016), yeast extract elicitation did not cause statistically significant changes in the fresh and dry weight of lettuce plants.

Some previous studies indicated that jasmonic acid elicitation can increase the production of some phytochemicals (like phenolic compounds or vitamin C) in basil and lettuce leaves (Złotek et al., 2014; 2016). Additionally, YE-elicited lettuce also showed an increase in total phenolic content, but not in vitamin C content (Złotek and Świeca, 2016). Unexpectedly, in the present study, neither the JA- nor YE-elicitation caused significant changes in the content of phenolic compounds in the marjoram herbs (Table 2). On the other hand, elicitation with jasmonic acid did not cause significant changes in the ascorbic acid content of the herbs studied, while a significant increase in the content of this antioxidant in the plants elicited with yeast extract was observed (Table 2).

In contrast to our results, in the study conducted by Ali et al. (2009), foliar spraying with some polyamines like putrescine, spermidine and spermine, which are biologically active compounds recognized as modulators of plant growth and development, resulted in an increase in the flavonoid contents in different organs of Origanum majorana plants. Therefore, as has been assumed by many researchers, the effect of elicitation depends largely on such factors as the kind of elicitors and the species of the plant elicited (Baenas et al., 2014; Zhao et al., 2005).

Other plant metabolites with specific dietary activities, whose level in the plant may be influenced by elicitation, are carotenoids and chlorophylls. The prohealth properties of these plant pigments have been associated with a reduction in the risk of cancer, heart disease, stroke, and cataracts (Caldwell and Britz, 2006). It is well known that carotenoids act as antioxidants (Kim et al., 2007), whereas the bioactive effect of chlorophyll is related to its ability to inhibit COX-1 and COX-2 enzymes (Reddy et al., 2005). 
In previous studies, some natural elicitors (yeast extract or willow bark extracts) caused an increase in the level of antioxidants such as phenolic compounds or chlorophylls (Złotek and Świeca, 2016; Gawlik-Dziki et al., 2013). This observation is partially confirmed by the result obtained in the present work, because the yeast extract elicitation resulted in a significant increase of chlorophyll content, but not phenolic compound content in the marjoram leaves (Table 2).

Due to its high content of antioxidants, marjoram has antioxidant properties, which largely determine the health-promoting value of this herb (Vallverdú-Queralt et al., 2015). It is well known that elicitation may affect the antioxidant capacity of plant food (Świeca, 2016; Złotek et al., 2016). Elicitation with jasmonic acid significantly improved the antioxidant activity of the extracts of the herb, which was determined using two different assays: DPPH free radical scavenging activity and reducing power (Fig. 1 and 2).

Our results perfectly corresponded with those reported by Kim et al. (2006), where the antioxidant activity against DPPH of sweet basil extracts obtained after methyl jasmonate application was 2.3 times greater than that of the control. Similarly, the study conducted by Malekpoor et al. (2016) indicated that spraying with jasmonic acid had a significant positive impact on the antioxidant activity of basil. Additionally, in the study conducted by Złotek and Świeca (2016), YE-elicited lettuce samples showed a significantly higher reducing power, as well as antiradical activity, compared to the control. These results were only partially confirmed in the current study, because the YE-elicitation improved the antiradical activity of marjoram, but had no positive impact on the reducing power of the marjoram extracts (Fig. 1 and 2).

The results obtained in the present study indicate that the increased antioxidant capacity of elicited marjoram was due to the higher level of bioactive compounds such as ascorbic acid, chlorophylls and carotenoids. The higher bioactive value of this herb after elicitation is associated with increased levels of ascorbic acid and chlorophylls (in the case of biotic elicitation) or carotenoids (in the case of abiotic elicitation).

\section{CONCLUSIONS}

In conclusion, elicitation could be an effective strategy for improving the level of some phytochemicals and the antioxidant activity of marjoram. A particularly valuable finding of this study is that natural elicitors such as yeast extracts can be equally effective in elevating the content of some bioactive compounds in this herbs.

\section{REFERENCES}

Ali, R. M., Abbas, H. M., Kamal, R. K. (2009). The effects of treatment with polyamines on dry matter and some metabolites in salinity - stressed chamomile and sweet majoram seedlings. Plant Soil Environ., 55(11), 477-483.

Angelova, Z., Georgiev, S., Roos, W. (2006). Elicitation of plants. Biotechn. Biotechnol. Equip., 20(2), 72-83.

Baenas, N., García-Viguera, C., Moreno, D. A. (2014). Elicitation. A tool for enriching the bioactive composition of foods. Molecules, 19(9), 13541-13563.

Brand-Williams, W., Cuvelier, M. E., Berset, C. (1995). Use of free radical method to evaluate antioxidant activity. Leben. Technol., 28, 25-30.

Caldwell, C. R., Britz, S. J. (2006). Effect of supplemental ultraviolet radiation on the carotenoid and chlorophyll composition of greenhouse-grown leaf lettuce (Lactuca sativa L.) cultivars. J. Food Compos. Anal., 19(6), 637-644.

Campos, F. M., Ribeiro, S. M. R., Della Lucia, C. M., Pinheiro-Sant'Ana, H. M., Stringheta, P. C. (2009). Optimization of methodology to analyze ascorbic and dehydroascorbic acid in vegetables. Quim. Nova, 32(1), 87-91.

De Román, M., Fernández, I., Wyatt, T., Sahrawy, M., Heil, M., Pozo, M. J. (2011). Elicitation of foliar resistance mechanisms transiently impairs root association with arbuscular mycorrhizal fungi. J. Ecol., 99(1), 36-45.

Gawlik-Dziki, U., Świeca, M., Dziki, D., Sugier, D. (2013). Improvement of nutraceutical value of broccoli sprouts by natural elicitors. Acta Sci. Pol. Hortorum Cultus., 12(1), 129-140.

Hossain, M., Brunton, N., Patras, A., Tiwari, B. (2012). Optimization of ultrasound assisted extraction of antioxidant compounds from marjoram (Origanum majorana L.) using response surface methodology. Ultrason. Sonochem., 19(3), 582-590. 
Złotek, U. (2017). Effect of jasmonic acid and yeast extract elicitation on low-molecular antioxidants and antioxidant activity of marjoram (Origanum majorana L.). Acta Sci. Pol. Technol. Aliment., 16(4), 371-377. http://dx.doi.org/10.17306/J.AFS.2017.0505

Kim, H.-J., Chen, F., Wang, X., Rajapakse, N. C. (2006). Effect of methyl jasmonate on secondary metabolites of sweet basil (Ocimum basilicum L.). J. Agric. Food Chem., 54(6), 2327-2332.

Kim, H.-J., Fonseca, J. M., Choi, J.-H., Kubota, C. (2007). Effect of methyl jasmonate on phenolic compounds and carotenoids of romaine lettuce (Lactuca sativa L.). J. Agric. Food Chem., 55(25), 10366-10372.

Kocira, A., Świeca, M., Kocira, S., Złotek, U., Jakubczyk, A. (2016). Enhancement of yield, nutritional and nutraceutical properties of two common bean cultivars following the application of seaweed extract (Ecklonia maxima). Saudi J. Biol. Sci. https://doi.org/10.1016/j. sjbs.2016.01.039

Lin, K.-H., Huang, M.-Y., Huang, W.-D., Hsu, M.-H., Yang, Z.-W., Yang, C.-M. (2013). The effects of red, blue, and white light-emitting diodes on the growth, development, and edible quality of hydroponically grown lettuce ( $\mathrm{Lac}$ tuca sativa L. var. capitata). Sci Hortic., 150, 86-91.

Malekpoor, F., Salimi, A., Pirbalouti, A. G. (2016). Effect of jasmonic acid on total phenolic content and antioxidant activity of extract from the green and purple landraces of sweet basil. Acta Pol. Pharm.-Drug. Res., 73(5), 1229-34.

Mulabagal, V., Ngouajio, M., Nair, A., Zhang, Y., Gottumukkala, A. L., Nair, M. G. (2010). In vitro evaluation of red and green lettuce (Lactuca sativa) for functional food properties. Food Chem., 118(2), 300-306.

Nowak, K., Ogonowski, J. (2010). Marjoram oil, its characteristics and application. Chemik, 64(7-8), 539-548.

Nurzyńska-Wierdak, R., Rożek, E., Bolanowska, K. (2012). Plon i jakość ziela melisy, majeranku oraz tymianku w zależności od sposobu uprawy w pojemnikach [The yield and quality of lemon balm, marjoram and thyme herb depending on the cultivation method]. Ann. Univ. Mariae Curie-Sklodowska Sect. EEE, 22(2), 1-11 [in Polish].

Oyaizu, M. (1986). Studies on products of browning reaction antioxidative activities of products of browning reaction prepared from glucosamine. Japan J. Nutr., 44, $307-315$

Prerna, P., Vasudeva, N. (2015). Origanum majorana L. Phyto-pharmacological review. Indian J. Nat. Prod. Resour., 6(4), 261-267.
Reddy, M. K., Alexander-Lindo, R. L., Nair, M. G. (2005). Relative inhibition of lipid peroxidation, cyclooxygenase enzymes, and human tumor cell proliferation by natural food colors. J. Agric. Food Chem., 53, 9268-9273.

Saxena, D., Jayant, S. K., Soni, K., Neekhra, K. (2016). Origanum majorana, a potential herb for functional food. Eur. J. Pharm. Med. Res., 3(2), 321-325.

Singleton, V. L., Rossi, J. A. (1965). Colorimetry of total phenolics with phosphomolybdic-phosphotungstic acid reagents. Am. J. Enol. Vitic., 16(3), 144-158.

Świeca, M. (2016). Elicitation and treatment with precursors of phenolics synthesis improve low-molecular antioxidants and antioxidant capacity of buckwheat sprouts. Acta Sci. Pol. Technol. Alim., 15(1), 17-28.

Vallverdú-Queralt, A., Regueiro, J., Alvarenga, J. F. R., Martinez-Huelamo, M., Leal, L. N., Lamuela-Raventos, R. M. (2015). Characterization of the phenolic and antioxidant profiles of selected culinary herbs and spices, caraway, turmeric, dill, marjoram and nutmeg. Food Sci. Technol., 35(1), 189-195.

Zhao, J., Davis, L. C., Verpoorte, R. (2005). Elicitor signal transduction leading to production of plant secondary metabolites. Biotechnol. Adv., 23(4), 283-333.

Złotek, U., Michalak-Majewska, M., Szymanowska, U. (2016). Effect of jasmonic acid elicitation on the yield, chemical composition, and antioxidant and anti-inflammatory properties of essential oil of lettuce leaf basil (Ocimum basilicum L.). Food Chem., 213, 1-7.

Złotek, U., Świeca, M., Jakubczyk, A. (2014). Effect of abiotic elicitation on main health-promoting compounds, antioxidant activity and commercial quality of butter lettuce (Lactuca sativa L.). Food Chem., 148, 253-260.

Złotek, U., Świeca, M. (2016). Elicitation effect of Saccharomyces cerevisiae yeast extract on main health-promoting compounds and antioxidant and anti-inflammatory potential of butter lettuce (Lactuca sativa L.). J. Sci. Food Agric., 96(7), 2565-2572.

Złotek, U., Szymanowska, U., Karaś, M., Świeca, M. (2016). Antioxidative and anti-inflammatory potential of phenolics from purple basil (Ocimum basilicum L.) leaves induced by jasmonic, arachidonic and $\beta$-aminobutyric acid elicitation. Int. J. Food Sci. Technol., 51(1). 